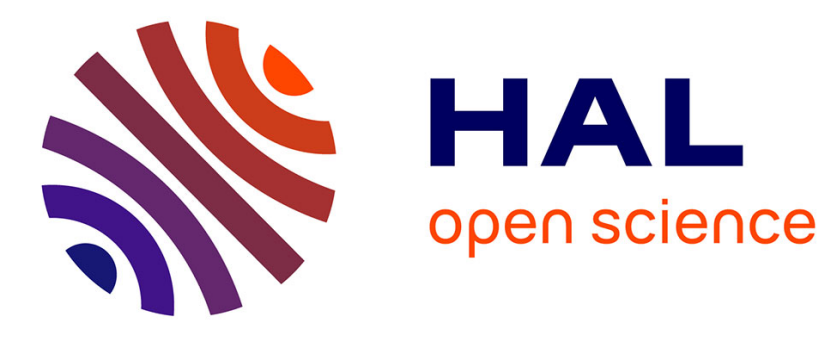

\title{
Is CCL18 a potential biomarker of type-2 asthma endotypes?
}

Helen Fouquet, Jonathan Giovannelli, Patricia de Nadaï, Joanne Balsamelli, Patrick Berger, Arnaud Bourdin, Pascal Chanez, Stéphanie Fry, Thierry Perez, Antoine Magnan, et al.

\section{To cite this version:}

Helen Fouquet, Jonathan Giovannelli, Patricia de Nadaï, Joanne Balsamelli, Patrick Berger, et al.. Is CCL18 a potential biomarker of type-2 asthma endotypes?. Journal of Asthma, In press, pp.1-9. 10.1080/02770903.2020.1861623 . hal-03046944

\section{HAL Id: hal-03046944 https://hal.science/hal-03046944}

Submitted on 29 Jul 2021

HAL is a multi-disciplinary open access archive for the deposit and dissemination of scientific research documents, whether they are published or not. The documents may come from teaching and research institutions in France or abroad, or from public or private research centers.
L'archive ouverte pluridisciplinaire HAL, est destinée au dépôt et à la diffusion de documents scientifiques de niveau recherche, publiés ou non, émanant des établissements d'enseignement et de recherche français ou étrangers, des laboratoires publics ou privés. 


\title{
Is CCL18 a potential biomarker of type-2 asthma endotypes?
}

\author{
Helen Fouquet, $M D^{\mathrm{a}, \mathrm{b} *}$, Jonathan Giovannelli, $M D, \mathrm{PhD}^{\mathrm{C} *}$, Patricia de Nadaï, PhD ${ }^{\mathrm{d}}$, Joanne Balsamelli, BIOT ${ }^{\mathrm{d}}$, \\ Patrick Berger, MD, PhD e,f, Arnaud Bourdin, MD, PhD f,g, Pascal Chanez, MD, PhD, ${ }^{\mathrm{f}, \mathrm{h}}$, Stéphanie Fry, MD ${ }^{\mathrm{f}, \mathrm{i}}$, \\ Thierry Perez, $M D^{a, d, f, j}$, Antoine Magnan, $M D, P h D^{f, k}$, Marina Pretolani, PharmD, $P h D$ ', Camille Taillé, MD, PhD ${ }^{f, m}$, \\ Anne Tsicopoulos, $M D^{f, i}$, and Cécile Chenivesse, $M D, \mathrm{PhD}^{\mathrm{f}, \mathrm{i}}$; on behalf of the COBRA study group \\ ${ }^{a} \mathrm{CHU}$ Lille, Service de Pneumologie et Immuno-allergologie, Centre de référence constitutif pour les maladies pulmonaires rares, \\ Lille, France; ${ }^{b} \mathrm{CHU}$ de Caen, Service de Pneumologie, Caen, France; ${ }^{\mathrm{c} G I O V A N N E L L I ~ e p i d e m i o l o g y}$ and clinical research counselling, \\ Lille, France; 'Univ. Lille, CNRS, Inserm, CHU Lille, Institut Pasteur de Lille, U1019-UMR9017-CIIL-Centre d'Infection et d'Immunité de \\ Lille, Lille, France; ${ }^{\mathrm{C} C e n t r e}$ de Recherche Cardio-Thoracique de Bordeaux, Inserm U1045, CIC1401, CHU de Bordeaux, Université de \\ Bordeaux, Bordeaux, France; ${ }^{\mathrm{f} C R I S A L I S / F-C R I N ~ n e t w o r k ; ~}{ }^{9}$ Inserm UMR1046, CHU de Montpellier, Département de Pneumologie et \\ Addictologie, Faculté de Médecine Montpellier Nîmes, Montpellier, France; ${ }^{\mathrm{h}}$ Aix Marseille Université, Clinique des bronches, allergie et \\ sommeil/APHM, C2VN Centre INSERM INRA UMR1062 Marseille, France; 'CHU Lille, Service de Pneumologie et Immuno-allergologie, \\ Centre de référence constitutif pour les maladies pulmonaires rares, Univ. Lille, CNRS, Inserm, CHU Lille, Institut Pasteur de Lille, \\ U1019-UMR9017-CIIL-Centre d'Infection et d'Immunité de Lille, Lille, France; ${ }^{j} \mathrm{CHU}$ Lille, Service d'Explorations fonctionnelles \\ respiratoires, Lille, France; 'Eniversité de Nantes, Inserm UMR 1087, CHU Nantes, Service de Pneumologie, Nantes, France; Inserm \\ UMR1152, Université de Paris, Paris Diderot, Faculté de Médecine, site Bichat, Laboratory of Excellence INFLAMEX, Université \\ Sorbonne Paris-Cité, Paris, France; ${ }^{\mathrm{m}} \mathrm{CHU}$ Bichat, Service de Pneumologie A - hôpital Bichat-Claude Bernard, Paris, France
}

\begin{abstract}
Objective: This exploratory cross-sectional study aimed to evaluate the associations between the chemokine ligand 18 (CCL18) blood level and phenotypic characteristics of asthma.

Methods: We evaluated in a sample of 173 asthmatic adult patients from the Cohort of Bronchial obstruction and Asthma (63.4\% women; median age $50 \pm$ interquartile range 27.5 years; median level of CCL18 was $44.1 \pm$ interquartile range $27.5 \mathrm{ng} / \mathrm{mL}$ ) the association between CCL18 blood level and allergic features of asthma using a multivariate analysis.

Results: We found an association between the log-transformed value of blood CCL18 and age $(+0.7 \%[0.1 ; 1.3]$ per 1 -year increase, $p=0.033)$, gender $(-25.1 \%[-42 ;-3.2]$ in women, $p=0.029)$, and nasal polyposis $(+38.1 \%[11.6 ; 70.9], p=0.004)$. No association was observed between CCL18 level and the other main phenotypic characteristics of asthma.

Conclusions: Our exploratory study suggests that CCL18 is not an effective biomarker of allergic asthma endotype but may rather be a biomarker of tissue eosinophilia as supported by its association with nasal polyposis.
\end{abstract}

Abbreviations: CCL18: Chemokine (C-C motif) ligand 18; COBRA: Cohort of Bronchial obstruction and Asthma; IgE: Immunoglobulins E

\section{KEYWORDS}

Asthma; allergic; phenotype; endotype; biomarker; chemokine; CCL18
Asthma is a heterogeneous disease involving multiple pathophysiological mechanisms called endotypes. A personalized approach to treatment of asthma aims to target specific immune pathways using biologic therapies. Selecting the right biologic therapy requires to determine which endotype is involved in an individual patient, in particular type 2 (T2)-endotypes, for which biologic therapies are available. T2-endotypes broadly consist of the allergic and eosinophilic endotypes, which are targeted by anti-IgE and anti-IL5/IL5R antibodies, respectively, and more recently anti-IL4R antibody. Currently, endotypes are characterized on the basis of clinical and biological features, called phenotypes. Basically, the allergic phenotype is defined by sensitization to aeroallergens and the presence of allergic rhinitis while the eosinophilic phenotype is designated by a blood eosinophils level above $300 / \mathrm{mm}^{3}$ and co-existence of nasal polyposis (1). Using these phenotypic criteria to choose a biologic therapy leads to $25 \%-39 \%$ of response failure $(2,3)$. Therefore, identifying effective biomarkers of endotypes remains of major interest in asthma. 
Table 1. Patient characteristics according to CCL18 level.

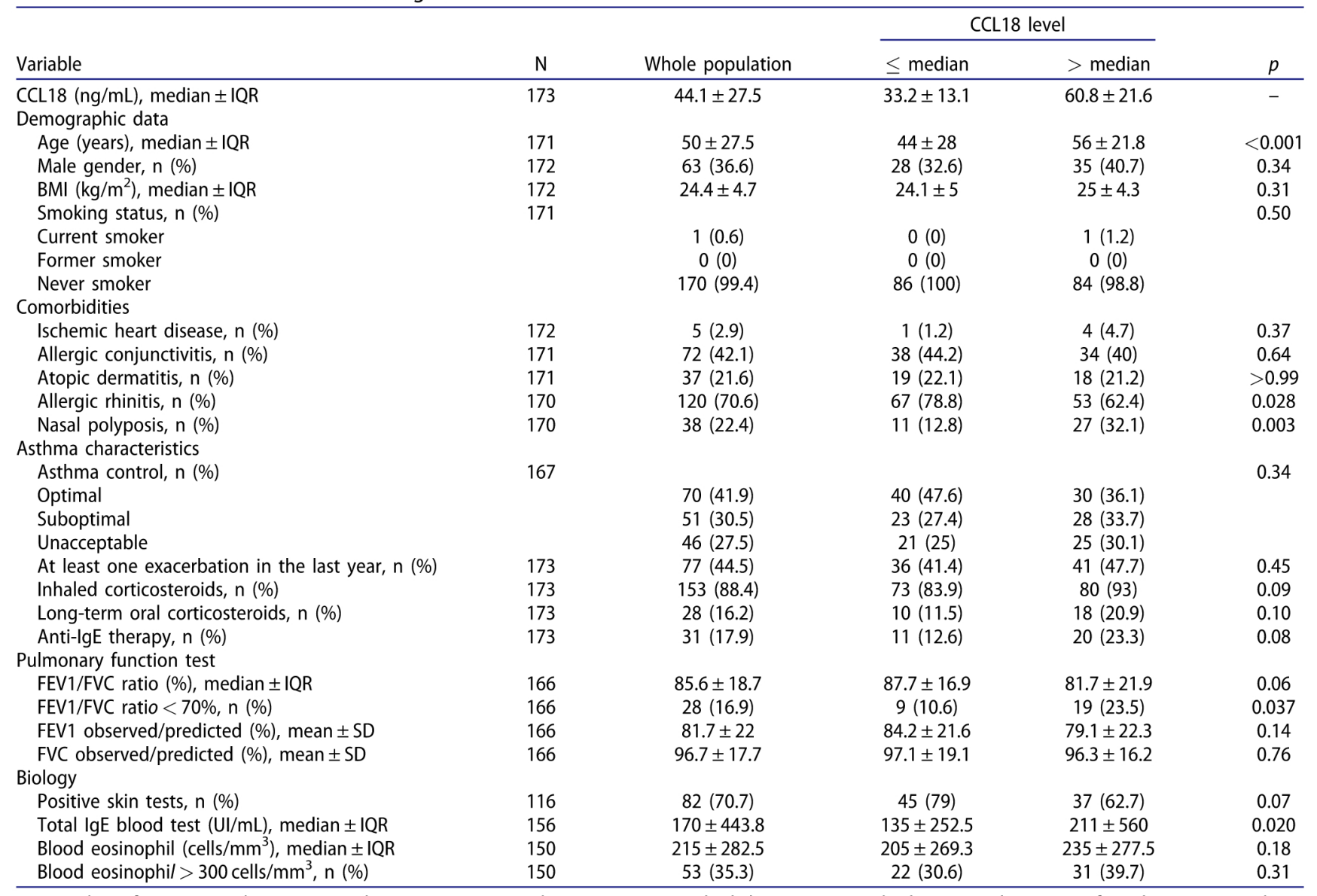

$\mathrm{N}$-number of patients with no-missing data; IQR—interquartile range; SD—standard deviation; BMI—body mass index; FEV1—forced expiratory volume in $1 \mathrm{~s} ; \mathrm{FVC}$-forced vital capacity.

Characteristics of patients with values lower or higher than the median of CCL18 were compared using Student's $t$ tests or Wilcoxon tests if non-normal distribution for quantitative variables, and using exact Fisher tests for qualitative variables.

The chemokine ligand 18 (CCL18) is a potential biomarker of allergic asthma. Indeed, it is elevated in bronchoalveolar lavage and serum from untreated allergic asthmatic patients (4) and in many allergic conditions, such as atopic dermatitis, allergic rhinitis and vernal conjunctivitis $(5,6)$. Moreover, CCL18 has a pro-T2 activity including the ability to recruit Th2 cells and basophils, to activate basophils and to induce macrophages alternative maturation (5). However, there is a lack of data on the relationship between CCL18 levels and asthma endotypes.

Biomarkers help for providing an understanding of the molecular pathways and the discovery of new targets for novel therapies. For clinical practice, biomarkers can be used for several purposes, in particular disease diagnosis and staging, assessment of disease progression and treatment response. Useful biomarkers must be strongly associated, and, beyond, accurately predict clinical disease outcomes leading to obtain high predictive values.

In order to evaluate CCL18 as a potential biomarker of asthma endotypes, this exploratory study aimed to evaluate, as a first step, the associations between CCL18 levels and phenotypic characteristics of asthma.

This cross-sectional study included a sample of patients from the Cohort of Bronchial obstruction and Asthma (COBRA), which included asthma patients aged between 18 and 85 years from January 2007 to December 2015 in 12 French academic institutions (7). All severities and levels of asthma control were included. The COBRA cohort was approved by the CPP Ile-de-France I ethics committee (number 09-11962) and all subjects gave their written informed consent.

The following data were collected: demographic and clinical characteristics including asthma control (GINA 2006 classification [optimal, suboptimal, unacceptable], at least one exacerbation in the last year), skin prick-tests with 11 aero-allergens, total immunoglobulins E (IgE) and blood eosinophil levels, and spirometry. Serum level of CCL18 was measured from the COBRA biological collection by Specific Enzyme Linked Immunosorbent assay according to 
Table 2. Association between CCL18 levels and patient characteristics.

\begin{tabular}{|c|c|c|c|c|}
\hline \multirow[b]{2}{*}{ Variable } & \multicolumn{2}{|c|}{ Univariate analysis } & \multicolumn{2}{|c|}{ Multivariate analysis $(n=133)$} \\
\hline & $\%$ change $[95 \% \mathrm{Cl}]$ & $p$ & $\%$ change $[95 \% \mathrm{Cl}]$ & $p$ \\
\hline \multicolumn{5}{|l|}{ Demographic data } \\
\hline Age, per 1-year increase & $1.2[0.7 ; 1.6]$ & $<0.001$ & $0.7[0.1 ; 1.3]$ & 0.033 \\
\hline Gender (reference $=$ male) & $-14.7[-27.3 ; 0.1]$ & 0.05 & $-25.1[-42 ;-3.2]$ & 0.029 \\
\hline BMI per $1 \mathrm{~kg} / \mathrm{m}^{2}$ increase & $2.0[-0.5 ; 4.7]$ & 0.12 & $0[-3.2 ; 3.2]$ & 0.98 \\
\hline \multicolumn{5}{|l|}{ Comorbidities } \\
\hline Ischemic heart disease & $82[15.3 ; 187.2]$ & 0.011 & $51.8[-5.7 ; 144.6]$ & 0.09 \\
\hline Allergic conjunctivitis & $-9.9[-23.1 ; 5.6]$ & 0.20 & $-6.5[-22 ; 12.1]$ & 0.47 \\
\hline Atopic dermatitis & $-12.9[-27.9 ; 5.3]$ & 0.16 & $-7.1[-25.9 ; 16.5]$ & 0.53 \\
\hline Allergic rhinitis & $-11[-25.1 ; 5.7]$ & 0.19 & $-9.6[-26.3 ; 10.9]$ & 0.34 \\
\hline Nasal polyposis & $49.9[25.3 ; 79.4]$ & $<0.001$ & $38.1[11.6 ; 70.9]$ & 0.004 \\
\hline \multicolumn{5}{|l|}{ Asthma characteristics } \\
\hline Asthma control (reference $=$ optimal) & - & - & - & - \\
\hline Suboptimal & $4.6[-13.6 ; 26.6]$ & 0.64 & $-1.4[-20.5 ; 22.5]$ & 0.90 \\
\hline Unacceptable & $10.8[-9 ; 34.9]$ & 0.31 & $-1.5[-21 ; 22.7]$ & 0.89 \\
\hline At least one exacerbation in the last year & $5.7[-9.6 ; 23.6]$ & 0.49 & - & - \\
\hline Inhaled corticosteroids & $27.1[-0.1 ; 61.7]$ & 0.05 & $17.3[-11.3 ; 55.2]$ & 0.27 \\
\hline Long-term oral corticosteroids & $16.2[-5.8 ; 43.4]$ & 0.16 & $3.5[-19.2 ; 32.8]$ & 0.78 \\
\hline Anti-lgE therapy & $10.6[-9.7 ; 35.4]$ & 0.33 & $12.4[-11.6 ; 42.9]$ & 0.34 \\
\hline \multicolumn{5}{|l|}{ Spirometry testing } \\
\hline FEV1/FVC ratio, per $1 \%$ increase & $-0.6[-1.2 ;-0.1]$ & 0.029 & $-0.1[-0.7 ; 0.6]$ & 0.80 \\
\hline FEV1/FVC ratio $<70 \%$ & $24[0.4 ; 53.2]$ & 0.047 & - & - \\
\hline FEV1 observed/predicted, per $1 \%$ increase & $-0.3[-0.7 ; 0]$ & 0.06 & - & - \\
\hline FVC observed/predicted, per $1 \%$ increase & $-0.2[-0.6 ; 0.3]$ & 0.44 & - & - \\
\hline \multicolumn{5}{|l|}{ Outcomes of asthma phenotype } \\
\hline Positive skin tests & $0.2[-19.2 ; 24.4]$ & 0.98 & - & - \\
\hline Total IgE blood test, per $100 \mathrm{UI} / \mathrm{mL}$ increase & $0.8[-0.7 ; 2.4]$ & 0.30 & $0.3[-1.3 ; 1.9]$ & 0.75 \\
\hline Blood eosinophil, per $100 \mathrm{cell} / \mathrm{mm}^{3}$ increase & $0.6[-0.6 ; 1.8]$ & 0.34 & - & - \\
\hline Blood eosinophil $>300$ cells $/ \mathrm{mm}^{3}$ & $16.5[-2.5 ; 39.1]$ & 0.09 & $3.2[-15 ; 25.3]$ & 0.75 \\
\hline
\end{tabular}

the manufacturer's instructions. Coating (MAB394 monoclonal antibody) and biotinylated (BAF394 polyclonal antibody) antibodies were provided by $R \& D$ system. Recombinant human CCL18 (394-PA; R\&D system) was used as standard diluted from $2000 \mathrm{pg} / \mathrm{ml}$ to $31.25 \mathrm{pg} / \mathrm{ml}$.

In order to evaluate the association between CCL18 levels and patients' characteristics, we log-transformed CCL18 values to obtain normalized distribution. Then, we studied associations using (i) univariate linear regressions, and (ii) a multivariate linear regression model. This model included outcomes of the disease-excluding collinear variables (e.g. allergic rhinitis with positive prick tests) —and was adjusted for potential confounding factors defined a priori (sex, age, height, body mass index, coronary heart disease, conjunctivitis, atopic dermatitis, oral and inhaled corticosteroids and anti-IgE therapy). Since CCL18 values were log-transformed, the regression coefficients were expressed as the percent of change in CCL18 levels [95\% confidence interval] per unit of change in the explanatory variable. To this end, they were backtransformed (multiplying by 100 and subtracting $100 \%)$. In addition, we performed a sensitivity analysis in patients with an unacceptable asthma control (only the univariate analysis was performed due to low number of patients). Statistical analyzes were performed using R software, version 3.6.2 ( $\mathrm{R}$ Core Team
(2019). R: A language and environment for statistical computing. R Foundation for Statistical Computing, Vienna, Austria). The threshold for statistical significance was set at $p<0.05$.

One hundred seventy-three patients were included, mostly women $(63.4 \%)$ with a median \pm interquartile range age of $50 \pm 27.5$ years (Table 1). A majority of subjects (88.4\%) received inhaled corticosteroids, $16.2 \%$ long-term oral corticosteroids, and $17.9 \%$ antiIgE therapy. Asthma control was unacceptable and suboptimal in $27.5 \%$ and $30.5 \%$ of patients, respectively. A total of $70.7 \%$ patients had at least one positive skin prick-tests, and $35.3 \%$ showed blood eosinophilia $>300$ cells $/ \mathrm{mm}^{3}$. The median level of CCL18 was $44.1 \pm 27.5 \mathrm{ng} / \mathrm{mL}$.

In univariate analysis, CCL18 level was associated with age $(+1.2 \%,[0.7 ; 1.6]$ per 1 -year increase, $p<0.001)$, ischemic heart disease $(+82 \%[15.3 ; 187.2]$, $p=0.011)$, nasal polyposis $(+49.9 \% \quad[25.3 ; 79.4]$, $p<0.001)$, and FEV1/FVC ratio $(-0.6 \%[-1.2 ;-0.1]$ per 1-percent increase, $p=0.029)$. In multivariate analysis, we observed an association with age $(+0.7 \%$ $[0.1 ; 1.3]$ per 1-year increase, $p=0.033)$, gender $(-25.1 \%[-42 ;-3.2]$ in women, $p=0.029)$ and nasal polyposis $(+38.1 \%$ [11.6; 70.9], $p=0.004)$ (Table 2). In patients with unacceptable asthma control, CCL18 level was associated with nasal polyposis $(+60.2 \%[11 ; 131.3], p=0.016)$ in univariate analysis (data not shown). 
In this study that investigated CCL18 as a potential biomarker of allergic asthma endotypes, we only observed a significant but moderate association between CCL18 level and nasal polyposis in multivariate analysis, as previously reported (8) in particular in eosinophilic nasal polyposis (9). We did not find any significant association between CCL18 and asthma control, phenotypic features of allergic asthma and blood eosinophilia neither in the whole population, nor in poorly controlled patients who were likely to have active airway inflammation. Other studies with larger samples might be able to observe statistically significant associations with these asthma outcomes, but the strength of the association, which must be high for a biomarker to be potentially useful, is independent of the statistical power and unlikely to be much higher than in our study.

The main limits of the study were the presence of missing data, the lack of induced sputum preventing from eosinophilic airway inflammation evaluation, and the heterogeneity in severity and level of control of asthma.

Conclusion: Although additional studies on homogeneous populations in terms of severity and treatments could improve the relevance of our results, our exploratory study suggests that CCL18 is not an effective biomarker of allergic asthma endotype. However, the link between CCL18 and nasal polyposis, an eosinophilic airway disease associated with a better response to anti-IL5R therapy, suggests to study CCL18 as a biomarker of eosinophilic asthma endotype using eosinophils count in induced sputum. In addition, CCL1 8 should be evaluated as a biomarker of response to type 2-targeted therapies, in particular the anti-IL5 therapies.

\section{Declaration of interest}

There are no specific conflicts of interest for this study.

Helen Fouquet, Jonathan Giovannelli, Patricia de Nadaï and Joanne Balsamelli declare no conflict of interest.

Patrick Berger declares grants from GSK, Novartis, Boehringer, AstraZeneca, Chiesi; personal fees from GSK, Novartis, Boehringer, AstraZeneca, Circassia, Sanofi and Menarini.

Arnaud Bourdin has an advisory board member, congress participant or study investigator, has previously received honoraria, grants or other forms of support from Astra Zeneca, GSK, Boeringher Ingelheim, Novartis, Teva, Regeneron, Chiesi Farmaceuticals, Actelion, Gilead, and Roche.

Pascal Chanez provided consultancy services for Boehringer Ingelheim, Johnson \& Johnson, GSK, Merck Sharp \& Dohme, AstraZeneca, Novartis, Teva, Chiesi, and Sanofi; has served on advisory boards for Almirall, Boehringer Ingelheim, Johnson \& Johnson, GSK,
AstraZeneca, Novartis, Teva, Chiesi, and Sanofi; has received lecture fees from Boehringer Ingelheim, Centocor, GSK, AstraZeneca, Novartis, Teva, Chiesi, Boston Scientific, and ALK-Abelló; and received industry-sponsored grants from Roche, Boston Scientific, Boehringer Ingelheim, Centocor, GSK, AstraZeneca, ALK-Abelló, Novartis, Teva, and Chiesi.

Stéphanie Fry declares interventions fees, expertise fees and congress support from GSK, Sanofi aventis, Santelys, SOS oxygene and Vitalaire.

Thierry Perez reports interventions, expertise, grants or congress support for or from AstraZeneca, Boehringer Ingelheim, Chiesi, GSK, Novartis, Nuvaira

Antoine Magnan reports congress supports from Novartis, Chiesi and AstraZeneca.

Marina Pretolani's institution has received funds from MedImmune Ltd, Roche and AstraZeneca

Camille Taillé reports grants, congress supports and personal fees from Astra Zeneca, GSK, Novartis, Teva, Chiesi, Sanofi.

Anne Tsicopoulos was invited speaker for ALK, Novartis et AstraZeneca.

Cécile Chenivesse reports interventions, expertise, grants or congress support from ALK-Abello, AstraZeneca, Boehringer Ingelheim, Chiesi, GlaxoSmithKlein, MEDA Pharma, Medexact, Novartis, Pierre Fabre, Pfizer, Roche, Sanofi, Santelys, TEVA.

\section{Funding}

This project was funded by the Bonus $\mathrm{H}$ from CHU Lille.

\section{Authors' contribution}

Helen Fouquet substantially contributed to conception and design of the study, acquisition of data, analysis and interpretation of data, participated in revising the manuscript for important intellectual content and gave final approval of the version to be submitted version.

Jonathan Giovannelli and Cécile Chenivesse substantially contributed to conception and design of the study, acquisition of data, analysis and interpretation of data, participated in drafting the manuscript and gave final approval of the version to be submitted version.

Patricia de Nadaï and Joanne Balsamelli substantially contributed to acquisition of data, analysis and interpretation of data, participated in revising the manuscript for important intellectual content and gave final approval of the version to be submitted version.

Patrick Berger, Arnaud Bourdin, Pascal Chanez, Stéphanie Fry, Thierry Perez, Antoine Magnan, Marina Pretolani, Camille Taillé, Anne Tsicopoulos substantially contributed to acquisition of data, participated in revising the manuscript for important intellectual content and gave final approval of the version to be submitted version.

\section{Data availability statement}

Data supporting the findings of this study are available within the article. Raw data can be provided upon justified request to the corresponding author. 


\section{Ethics approval and consent to participate}

The COBRA cohort was approved by the CPP Ile-de-France I ethics committee (number 09-11962) and all subjects gave their written informed consent.

\section{References}

1. Fahy JV. Type 2 inflammation in asthma-present in most, absent in many. Nat Rev Immunol. 2015;15(1): 57-65. doi:10.1038/nri3786.

2. Drick N, Seeliger B, Welte T, Fuge J, Suhling H. AntiIL-5 therapy in patients with severe eosinophilic asthma - clinical efficacy and possible criteria for treatment response. BMC Pulm Med. 2018;18(1):119. doi:10.1186/s12890-018-0689-2.

3. Bousquet J, Rabe $\mathrm{K}$, Humbert $\mathrm{M}$, Chung KF, Berger W, Fox H, Ayre G, Chen H, Thomas K, Blogg M, et al. Predicting and evaluating response to omalizumab in patients with severe allergic asthma. Respir Med. 2007; 101(7):1483-1492. doi:10.1016/j.rmed.2007.01.011.

4. de Nadaï P, Charbonnier A-S, Chenivesse C, Sénéchal S, Fournier C, Gilet J, Vorng H, Chang Y, Gosset P, Wallaert B, et al. Involvement of CCL18 in allergic asthma. J Immunol. 2006;176(10):6286-6293. doi:10. 4049/jimmunol.176.10.6286.
5. Chenivesse C, Tsicopoulos A. CCL18 - Beyond chemotaxis. Cytokine. 2018;109:52-56. doi:10.1016/j. cyto.2018.01.023.

6. Pirayesh A, Ferdosi S, Shirzad H, Amani S, Bahadivand Chegini $H$, Bagheri N, Sadeghian L, Torkamand F. Differential expression of CCL18 in moderate/severe and mild persistent allergic rhinitis and its correlation with disease parameters. J Immunoassay Immunochem. 2018;39(5):485-495. doi: 10.1080/15321819.2018.1506931.

7. Pretolani M, Soussan D, Poirier I, Thabut G, Aubier M, COBRA Study Group,. Clinical and biological characteristics of the French COBRA cohort of adult subjects with asthma. Eur Respir J. 2017;50(2): 1700019. doi:10.1183/13993003.00019-2017.

8. Peterson S, Poposki JA, Nagarkar DR, Chustz RT, Peters AT, Suh LA, Carter R, Norton J, Harris KE, Grammer LC, et al. Increased expression of CC chemokine ligand 18 in patients with chronic rhinosinusitis with nasal polyps. J Allergy Clin Immunol. 2012; 129(1):119-127.e9. doi:10.1016/j.jaci.2011.08.021.

9. Yao Y, Yang C, Yi X, Xie S, Sun H. Comparative analysis of inflammatory signature profiles in eosinophilic and noneosinophilic chronic rhinosinusitis with nasal polyposis. Biosci Rep. 2020;40(2). doi:10.1042/BSR20193101. 